\title{
Non-Thermal Radio Frequency Stimulation Inhibits the Tryptophan Synthase Beta Subunit in the Algae Chlamydomonas reinhardtii
}

\author{
Bennett Michael Butters, Gabriel Vogeli, Xavier A. Figueroa \\ Nativis Inc., Seattle, WA, USA \\ Email:xfigueroa@nativis.com
}

How to cite this paper: Butters, B.M., Vogeli, G. and Figueroa, X.A. (2017) NonThermal Radio Frequency Stimulation Inhibits the Tryptophan Synthase Beta Subunit in the Algae Chlamydomonas reinhardtii. Open Journal of Biophysics, 7, 8293.

https://doi.org/10.4236/ojbiphy.2017.73007

Received: April 18, 2017

Accepted: May 23, 2017

Published: May 26, 2017

Copyright $\odot 2017$ by authors and Scientific Research Publishing Inc. This work is licensed under the Creative Commons Attribution International License (CC BY 4.0).

http://creativecommons.org/licenses/by/4.0/

\begin{abstract}
To demonstrate the ability of the Nativis signal transduction technology (Butters et al. 2014) to modulate the expression of algae mRNA and protein, we tested if we can alter specific enzyme levels in Chlamydomonas reinhardtii. We inhibited the synthesis of the enzyme tryptophan synthase beta subunit (MAA7) by applying the signal derived from a published siRNA (Zhao et al. 2009). With lower levels of MAA7, Chlamydomonas reinhardtii can grow in the presence of the prodrug 5-Fluoroindole (5-FI), because less 5-Fluoroindole can be converted to the toxic 5-Fluoro-L-tryptophan (5-FT). We find a $24 \%( \pm 5 \%)$ increase of growth with the signal versus no signal. To see if that effect was due to the reduction of the amount of mRNA encoding MAA7, we used Real-Time Quantitative PCR (RT-QPCR) to measure the levels of MAA7 mRNA. To normalize the MAA7 mRNA level, we compared them to the levels of a mRNA that is not affected by the signal ( $G$ protein beta subunit-like polypeptide, Cblp). Two conditions increase the effectiveness of the signal. One can either treat the cell cultures during the logarithmic growth phase (starting the cultures at density of $0.104 \mathrm{OD}$ at $750 \mathrm{~nm}$ ). Or one can treat the cultures at a later stage of the logarithmic growth, but treating them for a longer time ( $8.7 \%$ versus $3.5 \%$ of the culture time). Under these conditions we found around a 50\% decrease in the mRNA levels for MAA7. Treating the cultures at the earlier growth phase or at a later growth phase is less effective, with only a $20 \%$ effect.
\end{abstract}

\section{Keywords}

Ultra Low Radio Frequency Energy, ulRFE, siRNA, Oil Production, Nativis Technology, MAA7: Beta Subunit of Tryptophan Synthase, Chlamydomonas reinhardtii 


\section{Introduction}

We used the Nativis technology [1] to alter gene expression in the algae Chlamydomonas (short for Chlamydomonas reinhardtii) [2]. A radio frequency fingerprint is taken from a chemical dissolved in an aqueous solution as described in [1]. The radiofrequency is then transmitted via an antenna array or coil to the targeted biological system. It has been shown that under certain conditions, the signal can affect the recipient molecule in a similar way as the chemical itself [1]. This non-thermal radio frequency stimulation technology has several advantages. One has good control over timing to affect metabolic pathways during the growth of an organism. The technology does not rely on the use of genetic modifications to affect biochemical pathways. This is especially valuable for growing algae in open ponds for oil production. Thus, this method does not generate ecological or political opposition since it avoids the cultivation of genetically modified algae (GMO) in open ponds.

Chlamydomonas is widely used in the laboratory to study the production of oil mainly because of its well characterized molecular biology and biochemistry [2] [3]. Our working hypothesis is that the siRNA signal transmitted to Chlamydomonas has the same effect on the mRNA as the physical siRNA. That is, it affects the cleavage of the mRNA via the RNA-induced silencing complex [3]. The mechanism of the interaction between the radiofrequency signal and the silencing complex (RISC) is not known.

To optimize the Nativis technology we targeted a well characterized enzyme in Chlamydomonas, the beta subunit of tryptophan synthase (MAA7) [4]. Zhao et al. have shown that the siRNA machinery functioning in Chlamydomonas, siRNA against MAA7 reduces the mRNA levels of MAA7 [4]. This leads to a reduction of the conversion of prodrug 5-FI to the highly toxic 5-FTryptophan. This allows the cells to grow in the presence of 5-FI. Here we present the optimization of the siRNA signal transduction to Chlamydomonas while we measure the growth rate and then fine tune the conditions measuring the amount of mRNA produced under the influence of the signal specific for the mRNA.

\section{Materials and Methods}

\subsection{Strains, Culture Conditions}

The strain CC-125 [5] of Chlamydomonas was obtained from the Chlamydomonas Resource Center, University of Minnesota, 140 Gortner Laboratory, St. Paul, MN 55108. Standard culture conditions were used [2]. Hutner's trace elements [2] were from Chlamy.org (http://www.chlamycollection.org/).

5-Fluoro-Indole (Sigma F9108-1G) was dissolved in Methanol. The control cultures receive the equivalent amount of methanol. All cultures were inactivated with Clorox before disposal.

\subsection{Growth of Chlamydomonas}

A batch of fresh TAP medium [2] was inoculated with a sample of stationary 


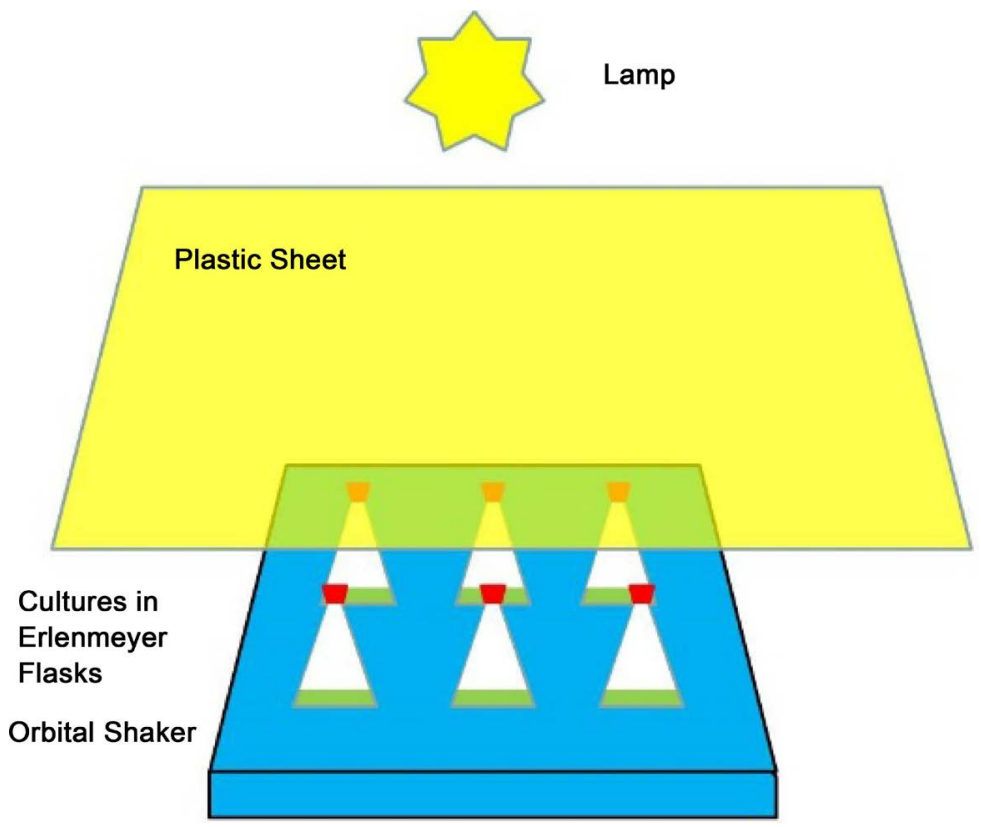

Figure 1. Experimental Setup with six $250 \mathrm{ml}$ Erlenmeyer Flasks on a rotatory shaker with yellow plastic between the flasks and the lights. The yellow plastic sheet covered the light source applied to the whole shaker setup.

phase cells. $30 \mathrm{ml}$ of cell suspension was then distributed into $250 \mathrm{ml}$ Erlenmeyers flasks and cultured on an orbital shaker (VWR 89032-092) at $100 \mathrm{rpm}$ under artificial light (GE Lighting 41624 60/A/PL Plant Light, Amazon.com) (Figure 1). A sheet of yellow plastic was placed between the light and the cultures, to remove wavelengths below $550 \mathrm{~nm}$. Papers placed on the plastic sheet were used to control the amount of light across the shaker platform. The amount of light was measured with a Mastech Professional Luxmeter, LX1010B (Amazon.com). The OD at $750 \mathrm{~nm}$ was measured with a Shimadzu photo spectrometer. Stationary growth was reached at an OD at $750 \mathrm{~nm}$ of 2.1 to 2.5. For continuous signaling, see below.

\subsection{Signals Recorded from MAA7 siRNA}

The signal Chl-001 was derived from the siRNA TGCCGGGGTAGTCCAGGC CGGC that silences MAA7 [4]. The siRNA was purchased from InVitrogen, (Scale: $20 \mathrm{~N}, 97.9 \mathrm{nM}$ ). Acquisition of the signal was from a solution of $5 \mathrm{nM}$ of siRNA in PBS (Gibco, 10010-049) as described [1].

\subsection{Transmission of the Signal}

The method has been described in detail [1]. In short, the cultures were transferred into glass tubes (VWR 60856-132) and inserted into a Helmholtz coil in a Quartet Reactor (Figure 2). The controls were treated identical but were kept in a silent coil. MAA7 siRNA signal transmission was at 70 mGauss for 20 to 30 minutes, either once or twice daily. Sometimes the cultures were vortexed in the glass tubes for 20 seconds before or/and after being exposed to the signal. The Voyager we used for these experiments was an early version to the one described 


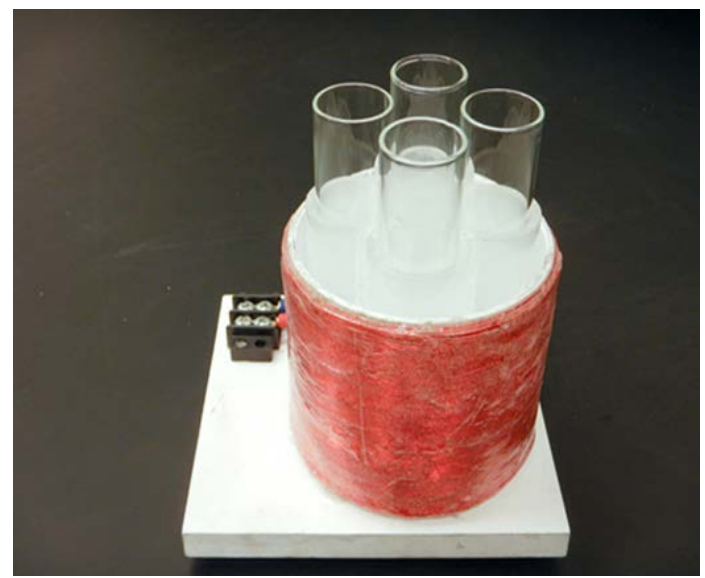

Figure 2. Quartet reactor: One Helmholtz coil can treat four $30 \mathrm{ml}$ samples that are in large glass tubes.

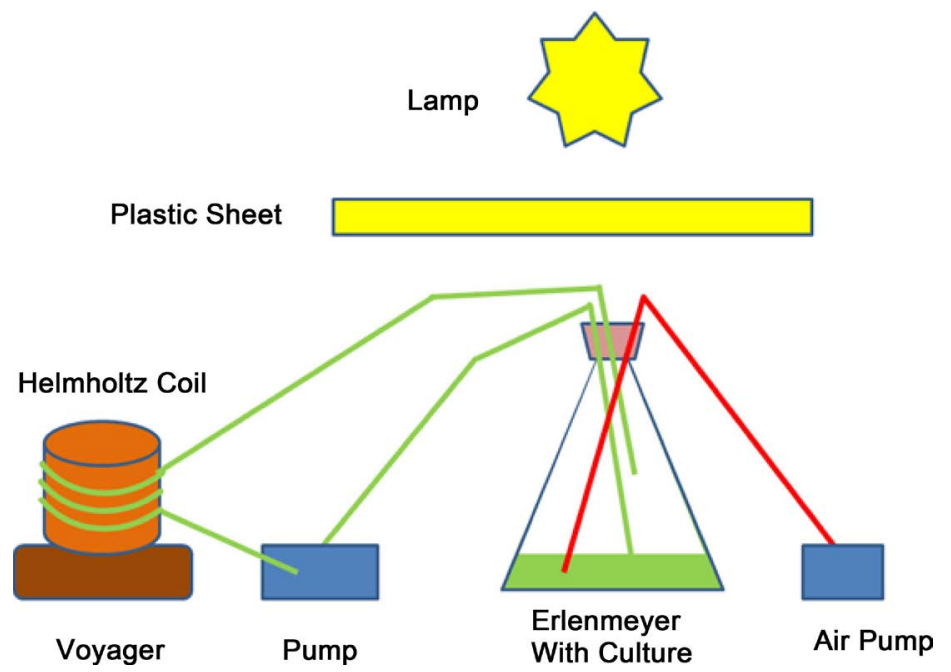

Figure 3. Experimental setup for the continuous transmission of the signal. The total culture volume was $400 \mathrm{ml}$ with $135 \mathrm{ml}$ of cell suspension in the tubing.

[1], but it had the same specifications. The exposure of the cultures to the signal was around $3 \%$ of the total culture time.

\subsection{Continuous Signaling}

To increase the exposure time of the culture to the signal, we used continuous signaling (Figure 3). This increased the exposure time to the signal to $8.8 \%$ of the culture time. The cell suspension was pumped at $16 \mathrm{ml} / \mathrm{min}$ through $1 / 4 \mathrm{inch}$ tubing (VWR 60985-528) wound 4 times lengthwise around the Helmholtz coil. The main cell culture was in a $250 \mathrm{ml}$ plastic Erlenmeyer flask under continuous illumination. The cells were kept in suspension by bubbling air through the solution. (Liquid pump: VWR: 57951-016, Elite 800 Air Pump, Amazon.com Air Stone, Air-Cylinder, VWR: 470103-670).

\subsection{Shielding from External Magnetic Fields}

The orbital shaker produces $\sim 20$ mGauss external field that was shielded with 
mu-metal sheets placed between the flask and the shaker. The Vortex Mixer (VWR 10153-838) generated an external magnetic field of up to 1500 mGauss, therefore we modified the vortexer to run on DC current. The shaker platforms for signal cultures and control cultures were 8 feet apart to avoid interference between the control cultures, signal cultures and potential interferences between other components.

\subsection{Isolation of RNA and Real-Time Quantitative PCR (RT-QPCR)}

Cell suspensions of $2.5 \mathrm{ml}$ were collected and mixed with $100 \mu \mathrm{l}$ RNAlater (Ambion AM 7020). $30 \mu$ Plant RNA Isolation Aid (Ambion AM9690M) was added and the RNA was recovered following the RNAqueous Kit from Ambion (AM9690M). RT-QPCR was done with an ABI Prism 7000 using the TaqMan ${ }^{\varnothing}$ One-Step RT-PCR Master Mix Reagents Kit (ABI 4309169) with the VIC and FAM Kit (ABI 4331348) using custom primers (ABI 4332078) designed to detect tryptophan synthase beta subunit (MAA, Genbank: XM_001703345) and the control gene: $G$ protein beta subunit-like polypeptide (Cblp, Genbank: X53574). $5 \mu \mathrm{l}$ and $2 \mu \mathrm{l}$ RNA was used in a final volume of $50 \mu \mathrm{l}$ with the first incubation at $48^{\circ} \mathrm{C}$ for $30 \mathrm{~min}$, then $10 \mathrm{~min}$ at $95^{\circ} \mathrm{C}$ followed by 40 cycles of $95^{\circ} \mathrm{C}$ for $15 \mathrm{sec}$ and $60^{\circ} \mathrm{C}$ for $15 \mathrm{sec}[6]$.

The RT-QPCR data from both sets of primers were used to calculate the fold increase in the mRNA levels for MAA7 by the delta-delta method [6] [7] [8]. Errors were calculated using standard error propagation, see also [4]. All calculations were done using Excel Spreadsheets (Microsoft, Windows).

\section{Results}

While optimizing the signal transmission to cultures of Chlamydomonas we found conditions that were effective in reducing the level of the enzyme MAA7. We initially measured the increased growth in 5-FI media under the influence of the signal Chl-001. Once we found conditions that worked, we determined the reduction of a specific mRNA under the influence of the signal using RT-QPCR.

\subsection{Selection of 5-Fluoro-Indole Concentrations in Growth Media without Signal}

To determine the concentration of 5-Fluoro-Indole to use in our experiments, we generated a dose response curve (Figure 4). We started the cultures with a cell density of $0.009 \mathrm{OD}$ at $750 \mathrm{~nm}$ and in $0,5,10,15$ and $20 \mu \mathrm{M}$ 5-FI. We measured the growth after 3 days. Compared to controls with no pro-drug, a concentration of $5 \mu \mathrm{M} 5$-FI inhibited growth partially. Growth was completely inhibited at $10 \mu \mathrm{M} 5$-FI and above. We used a dose of $5 \mu \mathrm{M}$ 5-FI for subsequent experiments with the signal.

\subsection{Signaling at the Early Stages of Growth in $5 \mu \mathrm{M}$ 5-Fluoro-Indole Enhances Growth}

The cultures were started at a low cell density of $0.007 \mathrm{OD}$ at $750 \mathrm{~nm}$ and the 
Dose Vs. Growth Inhibition

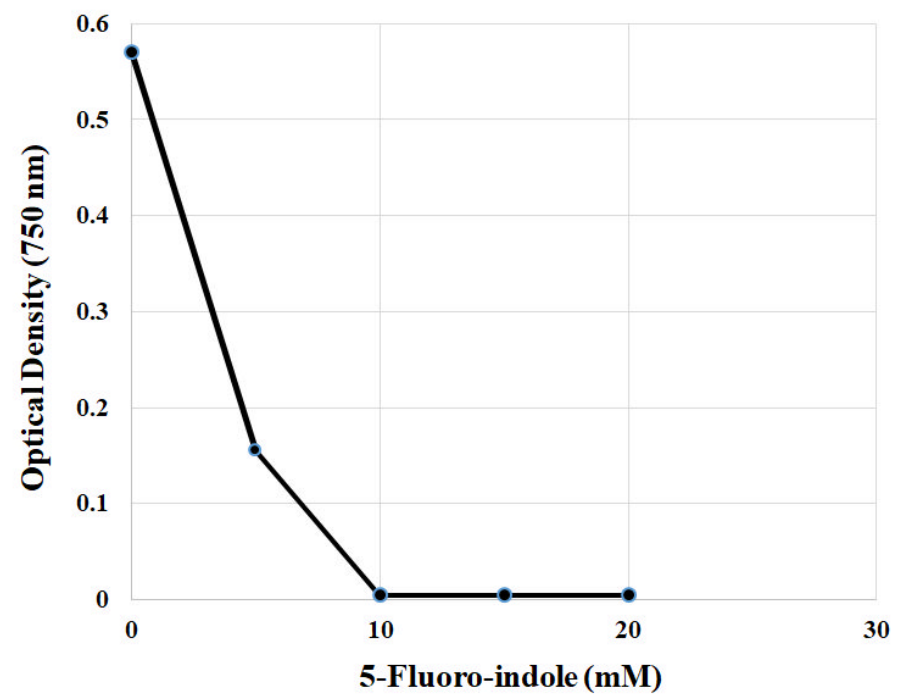

Figure 4. Growth after 3 days with different levels of 5-Fluoro-Indole in the media. Final Density of cell cultures after 3 days is shown. The cultures were started with a cell concentration of $0.009 \mathrm{OD}$ at $750 \mathrm{~nm}$. No Signal was applied.

Table 1. Optical Density (OD) Measures of Algae Growth.

\begin{tabular}{cccccc}
\hline & Start & Day 1 & Day 2 & Day 3 & Day 4 \\
\hline Chl-001, 5-Fl & 0.007 & 0.019 & 0.207 & 0.629 & 2.165 \\
Control & 0.007 & 0.018 & 0.189 & 0.606 & 1.762 \\
5-FI & 0.007 & 0.018 & 0.184 & 0.507 & 2.055 \\
\hline Chl-001, 5-Fl & Standard Deviation $( \pm)$ & & & \\
Control, & & 0.001 & 0.008 & 0.034 & 0.051 \\
5-FI & & 0.001 & 0.008 & 0.071 & 0.202 \\
& & 0.001 & 0.008 & 0.064 & 0.102 \\
\hline \% Increase in Growth with Chl-001 Signal & & \\
\hline \% of 5-Fl Control & & 0.001 & 0.023 & 0.122 & 0.11 \\
Standard Deviation $( \pm)$ & & 3.711 & 12.552 & 24.017 & 5.347 \\
\hline
\end{tabular}

growth was monitored for 4 days (Table 1 ). At day 4 , the cultures reached saturation. To administer the signal, the cell suspensions were transferred into large test tubes, vortexed first for $20 \mathrm{sec}$. They were then exposed to the signal Chl-001 at 70 mGauss in a Helmholtz coil (Figure 2) for $20 \mathrm{~min}$, twice a day; this translates to a total exposure period to the signal of $3.5 \%$ of the culture time. The 5-Fluoro-Indole was added to the cell culture at day 2 and the cell density was measured just after the addition of the prodrug. Under the influence of the signal, the cell mass increased by $24 \%$ at day 3 compared to the control. 


\subsection{Applying the Signal to the End Stages of Growth Reduces mRNA Levels for MAA7}

We started the culture at a high cell density of $0.502 \mathrm{OD}$ at $750 \mathrm{~nm}$. The Signal Chl-001 was applied at 70 mGauss, 4 times for 25 min during 2 days. This amounts to $3.5 \%$ of the culture time. The cultures reached saturation at around $2.1 \mathrm{OD}$ at $750 \mathrm{~nm}$ in one day. After 2 days, we measured mRNA levels by RT-QPCR (Table 2). Ct is the number of PCR cycles needed to reach a threshold level of PCR product. The more PCR cycles needed (e.g. higher Ct values), the less starting mRNA was in the sample [6] [7] [8]. The delta-delta calculations were used to determine the fold increase/decrease of a mRNA [6] [7] [8]. Table 2 shows the Ct data of the RT-QPCR and the calculated delta-delta values. Signal and control with cultures starting at high concentrations $(\mathrm{N}=3)$. Transmission was twice for $25 \mathrm{~min}$ at $70 \mathrm{mGauss}$. Two sets of primers were used, one set for MAA7 and one set for the control Cblp (G protein beta subunit-like polypeptide, Genbank: X53574). There is a $23 \%$ reduction in MAA7 mRNA levels when treating cultures during the later stages of growth. For the next experiment, we decided to use a starting cell density that reflects logarithmic growth phase of Chlamydomonas.

\subsection{Applying the Signal during the Logarithmic Phase of Growth Is More Effective at Reducing mRNA Levels for MAA7}

The cultures were started at a density of $0.104 \mathrm{OD}$ at $750 \mathrm{~nm}$ without the prodrug 5-Fluoro-Indole. The Signal Chl-001 was given 4 times for $20 \mathrm{~min}$ at 70 mGauss, evenly spaced over the 2 days. The signal exposure time is $3.6 \%$ of the total culture time. RT-QPCR was used to measure the levels of MAA7 mRNA that is the target of the signal Chl-001 and compared it with the levels of Cblp mRNA that is not affected by the signal. The comparison is done by the delta-delta method which calculated the fold increase of the experimental mRNA compared to the control mRNA [6] [7] [8]. After two days all the cultures reached saturation at $1.6 \mathrm{OD}$ at $750 \mathrm{~nm}$, there was no significant difference be-

Table 2. RT-QPCR data and results of delta-delta calculations.

\begin{tabular}{ccc}
\hline & MAA & Cblp \\
\cline { 2 - 3 } Primers & Ct & Ct \\
\hline Chl-001 & 29.403 & 25.362 \\
Chl-001 & 28.385 & 24.754 \\
Chl-001 & 28.194 & 24.853 \\
Control & 27.832 & 24.947 \\
Control & 28.108 & 24.796 \\
Control & 27.872 & 24.488 \\
Results of delta-delta calculations & & \\
Fold decrease in MAA7 mRNA levels [6] [7] [8] & & 0.228 \\
Standard Deviation $( \pm)$ & & 0.778 \\
\hline
\end{tabular}


Table 3. RT-QPCR data and results of delta-delta calculations, $\mathrm{n}=3$.

\begin{tabular}{|c|c|c|}
\hline \multirow{2}{*}{ Primers } & MAA & Cblp \\
\hline & $\mathrm{Ct}$ & $\mathrm{Ct}$ \\
\hline Chl-001 & 34.032 & 28.828 \\
\hline Chl-001 & 34.281 & 28.474 \\
\hline Chl-001 & 34.539 & 29.111 \\
\hline Control & 32.479 & 27.633 \\
\hline Control & 33.735 & 28.988 \\
\hline Control & 33.619 & 28.738 \\
\hline \multicolumn{3}{|c|}{ Results of delta-delta calculations } \\
\hline Fold Decrease in MAA7 mRNA [6] [7] [8] & & 0.428 \\
\hline Standard Deviation [6] & & 1.081 \\
\hline
\end{tabular}

tween the cultures (data not shown). Table 3 shows the $\mathrm{Ct}$ values (threshold value) of the RT-QPCR [8]. Ct is the number of PCR cycles need-ed to reach a threshold level of a PCR product. The more PCR cycles needed (e.g. higher Ct values), the less starting mRNA is in the sample [6] [7] [8]. Table 3 also shows the results of the delta-delta calculation. There is a $43 \%$ decrease in mRNA levels of MAA7 in Chl-001 signal treated cultures compared to the control cultures that did not receive the signal.

\subsection{Applying the Signaling for Longer Times at the Later Logarithmic Growth is Effective in Reducing MAA7 mRNA Levels}

We started the cultures at $0.336 \mathrm{OD}$ at $750 \mathrm{~nm}$ and gave the signal Chl-001 at 70 mGauss continuously (Figure 3). Since only a portion of the culture is at any time in the Helmholtz coils, this amounts to $8.7 \%$ of the culture time the cells were exposed to the signal. The mRNA levels were determined after $18 \mathrm{hrs}$. The control culture had reached $0.800 \mathrm{OD}$ at $750 \mathrm{~nm}$ and the treated culture reached $0.885 \mathrm{OD}$ at $750 \mathrm{~nm}$.

\section{Discussion}

To demonstrate the effectiveness of the Nativis Signal transmission strategy [1], we transmitted the signal Chl-001derived from a siRNA that is known to inhibit the enzyme MAA7 [4] to cultures of the algae Chlamydomonas. The signal Chl-001 reduced the amount of MAA7 under certain conditions. Here we will first discuss the optimization of cultures and signal application using as a measure cell density. Then we will discuss the use of RT-QPCR to find the optimal time window in the growth of Chlamydomonas to treat algae.

\section{1. siRNA Selection and Signal Application}

We used a published siRNA [4] that silences the tryptophan synthase beta sub- 
unit (MAA7). If MAA7 is inhibited, Chlamydomonas can grow in the presence of $5 \mu \mathrm{M}$ 5-Fluoro-Indole [4]. The analysis of the growth of Chlamydomonas in 5 $\mu \mathrm{M} 5$-FI, while under the stimulus of signal transmission makes this system a simple and fast way to optimize the signaling conditions.

To transmit the signal to the cell suspension, we used an early prototype of the "Voyager" system described in [1]. Transmission of the signal to the culture was for 20 or 25 min twice a day. This amounted to an exposure of around $3 \%$ of the total culture time. To increase the exposure time, we tested continuous signal transmission. This is closer to a setup that would be used in a commercial setup in the field (Figure 3). For continuous signal transmission, we replaced the orbital shakers with an air bubbling system and we pumped the cell suspension continuously through tubing wound around the Helmholtz coil. The diameter of the tube and the pump speed determined the residence time of the cells in the Helmholtz coil. We calculated that the total exposure time was around $8.8 \%$ of the culture time.

During our optimization we had to modify the culture setup of Chlamydomonas. This included the reduction of magnetic interference and the removal of the near UV component from the light source. Most laboratory equipment produces large amounts of magnetic fields, especially the Vortex, but also the orbital shakers and the fluorescent lights. To reduce the magnetic fields, the shaker platforms were covered with mu-metal. We modified the vortex to run on DC current. We replace the fluorescent lights with candescent lights and a cut-off filter (yellow plastic sheet).

To reduce the cross interference of the imprinted magnetic signature between the experimental cell cultures and the control cultures we moved the cultures 5 feet apart.

Something that became clear during our experiment was that Chlamydomonas cultures change their response to the signal depending on the growth stage at which one starts to treat the cultures. To test the signal during different growth phases, we used different starting concentrations of cells. Low initial cell density reflects the early growth phase. We also tested the logarithmic growth phase and the late growth phase for the effect of the signal on mRNA levels.

\subsection{Overcoming 5-Fluoro-Indol Inhibition with the Signal Chl-001 at the Early Stages of Growth}

In a culture with 5-FI, we expected that the signal enhances the growth of the cultures, since it will reduce the enzyme 5-Indole-Tryptophan synthetase (MAA7) and therefore, less of the toxic 5-FT will be produced. We chose to do the initial testing of the down regulation of MAA7 mRNA by the siRNA signal by growing the cultures with 5 -Fluoro-Indole. We followed the growth by measuring the OD at $750 \mathrm{~nm}$. This is a fast way to determine if the signal has an effect, while measuring mRNA levels is quite time consuming. Initially, we tested the effect of the signal on the growth of cultures with $10 \mu \mathrm{M}$ 5-FI starting at low initial density ( $0.01 \mathrm{OD}$ at $750 \mathrm{~nm}$ ). At $10 \mu \mathrm{M}$ of 5-FI the cells did not grow, the 
signal had no effect (Data not shown). Therefore, we determined the growth of Chlamydomonas at different concentrations of 5-FI (Figure 4). At $5 \mu \mathrm{M} \mathrm{5-FI}$ there is some growth and we decided to use that concentration to determine if the signal could overcome the partial growth inhibition of 5-FI.

We started to treat the cultures with the signal Chl-001 at low cell density $(0.007 \mathrm{OD}$ at $750 \mathrm{~nm})$ and grew it without 5-FI for 2 days (Table 1$)$. At day 2 we added $5 \mu \mathrm{M} 5$-FI. At that time, the cells had grown to $0.184 \mathrm{OD}$ at $750 \mathrm{~nm}$ with the signal compared to 0.207 OD without the signal. We assume that is due to the reduced production of tryptophan with the signal. When we apply the selective prodrug 5-FI at day 2 we find that the growth during the following days has been enhanced by $24 \%$ at day 3 with the signal. We assume that the control cells grew less, since they generated more toxic 5-FT. However, the use of the prodrug is complicated by the fact that the cells need to produce viable levels of tryptophan to sustain growth, especially in competition with the prodrug levels. Therefore, for the remainder of the experiments, we omitted the prodrug and measured only mRNA levels for the enzyme MAA7.

For accurate measurements of the effect of the signal, we determined the levels of the mRNA for MAA7 in the cultured cells using RT-QPCR. To normalize the mRNA levels of MAA7, we used the levels of Cblp ( $G$ protein beta subunit-like polypeptide). Cblp is not affect by the signal. We used the standard delta-delta method to calculate the fold increase/decrease of MAA7 [6] [7] [8] under the influence of the signal.

\subsection{Signal Applied during the Late Growth Phase}

Table 2 shows the RT-QPCR data of cultures that were started at an OD of 0.5 . The cultures were treated for 24 hours. At that time they all had reached saturation at $2.1 \mathrm{OD}$ at 750 . Both, the culture that received the signal and the one without signal grew at the same rate (data not shown). After they had all reached saturation at $2.1 \mathrm{OD}$ at 750 . The mRNA was extracted and RT-QPCR was carried out with the primers for MAA7 and the primers for the internal control, Cblp (Table 2). The summary for the delta-delta calculations of the RT-QPCR data are also shown in Table 2. Under this conditions, the mRNA levels for MAA7 decreased by $23 \%$.

\subsection{Signal Applied during the Late Growth Phase}

To treat the cultures during the logarithmic growth phase, the cultures of Chlamydomonas were started at a density of $0.104 \mathrm{OD}$ at $750 \mathrm{~nm}$. The signal was applied the first time at the start of the experiment and then in $12 \mathrm{hr}$ intervals. Both, the culture that received the signal and the one without signal grow at the same rate (data not shown). After 2 days the mRNA was extracted and RT-QPCR was carried out with the experimental primers for MAA7 and the primers for the internal control, Cblp (Table 3). The summary for the delta-delta calculations of the RT-QPCR data are also shown in Table 3. There was a $42 \%$ decrease in mRNA for MAA7 with the signal. 


\subsection{Signal Applied during the Late Growth Phase}

Applying the signal continuously leads to an exposure of the total cell suspension for $8.8 \%$ of the culture time. A big part of the culture volume is not exposed the Helmholtz coil (Figure 3), but is in tubing and the culture vessel. However, the continuous setup reflects most closely a setup that one would use in an industrial application. In our setup, the culture was pumped through the coil and back into the growth vessel for 18 hours (Figure 3, Table 4). The control setup was in a different room with slightly different temperatures. This explains the small difference in the cell density reached after $19 \mathrm{hrs}$. Two samples were collected after $19 \mathrm{hrs}$. The RT-QPCR data and the results of the delta-delta calculations are shown in Table 4. There is a 57\% reduction of the mRNA for MAA7 with an error of $11 \%$ (calculated STDEV).

Two conditions increase the effectiveness of the signal (Table 5). Either starting at an intermediate culture density in the logarithmic growth phase $(0.104$ $\mathrm{OD}$ at $750 \mathrm{~nm}$ ) or at higher starting density, but treating the cultures for a longer time (8.7\% of the culture time versus $3.5 \%)$. Under these conditions one can expect to see a $\sim 50 \%$ decrease in the mRNA levels for MAA7. Starting signal transmission early during growth or at the end of the growth phase is less effective.

Table 4. RT-QPCR after $18 \mathrm{hrs}$ of continuous irradiation and fold decrease of MAA mRNA [6] [7] [8]*.

\begin{tabular}{|c|c|c|}
\hline \multirow{2}{*}{ Primers } & MAA & Cblp \\
\hline & $\mathrm{Ct}$ & $\mathrm{Ct}$ \\
\hline Chl-001 & 26.1551 & 22.3869 \\
\hline Chl-001 & 26.2375 & 22.3605 \\
\hline Control & 24.1678 & 21.1243 \\
\hline Control & 24.2829 & 21.1931 \\
\hline \multicolumn{3}{|c|}{ Results of delta-delta calculations } \\
\hline Fold Decrease in MAA7 mRNA levels [6] [7] [8] & & 0.571 \\
\hline Standard Deviation [6] & & 0.113 \\
\hline
\end{tabular}

${ }^{*} \mathrm{n}=1$, but two samples were withdrawn and analyzed by RT-QPCR.

Table 5. Summary of the experiments.

\begin{tabular}{|c|c|c|c|c|c|c|c|c|c|}
\hline $\begin{array}{l}\% \text { Time } \\
\text { in Coil }\end{array}$ & $\begin{array}{c}\% \\
\text { Change }\end{array}$ & $\begin{array}{l}\text { Signaling during } \\
\text { Growth Phase }\end{array}$ & $\begin{array}{l}\text { Minutes in } \\
\text { Coil }\end{array}$ & $\begin{array}{l}\text { Minutes in } \\
\text { Culture }\end{array}$ & $\begin{array}{l}\text { Days in } \\
\text { Culture }\end{array}$ & $\begin{array}{l}\text { Start OD } \\
\text { at } 750 \mathrm{~nm}\end{array}$ & $\begin{array}{c}\text { End OD } \\
\text { at } 750 \\
\text { nm }\end{array}$ & $\begin{array}{l}\text { Control vs. } \\
\text { Signal }\end{array}$ & \\
\hline 3.7 & 24 & Early & 160 & 4320 & 3 & 0.007 & 0.629 & $\mathrm{n}=3 / \mathrm{n}=3$ & Cells \\
\hline 3.5 & 23 & Late & 50 & 1440 & 1 & 0.502 & 2.14 & $\mathrm{n}=3 / \mathrm{n}=3$ & mRNA \\
\hline 3.6 & 42 & $\log$ & 100 & 2760 & 1.92 & 0.104 & 1.68 & $\mathrm{n}=3 / \mathrm{n}=3$ & mRNA \\
\hline 8.7 & 57 & $\log$ & 97 & 1110 & 0.77 & 0.336 & 0.885 & $\mathrm{n}=1 / \mathrm{n}=1$ & mRNA \\
\hline
\end{tabular}




\section{Conclusion}

We found conditions for the Nativis Signal Technology [1] to reduce the mRNA levels of the enzyme MAA7 up to 50\% compared with untreated controls. The Nativis technology is an environmentally friendly technology that will be easy to control and to apply in a commercial setup. A major advantage of the technology is that it does not use genetical modifications to increase oil production. Thus it does not generate ecological or political opposition to the cultivation of genetically modified algae (GMO) in open ponds. Our next step will be to use signals that affect enzymes that can change the levels of oil production in algae.

\section{Acknowledgements}

Alan Herr designed the coils and reduced the electromagnetic footprint of the equipment. Many individuals, both past and present employees at Nativis, have contributed to the work. We would like to thank David Matteson and Steve Pope for edits and feedback on the manuscript.

\section{References}

[1] Butters, J.T., Figueroa, X.A. and Butters, B.M. (2014) Non-Thermal Radio Frequency Stimulation of Tubulin Polymerization in Vitro: A Potential Therapy for Cancer Treatment. Open Journal of Biophysics, 4, 147-168.

[2] Harris (1989) The Chlamydomonas Sourcebook.

[3] Carthew, R.W. and Sontheimer, E.J. (2009) Origins and Mechanisms of miRNAs and siRNAs. Cell, 136, 642-655. https://doi.org/10.1016/j.cell.2009.01.035

[4] Zhao, T., Wang, W., Bai, X. and Qi, Y. (2009) Gene Silencing by Artificial micrornas in Chlamydomonas. Plant Journal, 58, 157-164.

https://doi.org/10.1111/j.1365-313X.2008.03758.x

[5] Pröschold, T., Harris, E.H. and Coleman, A.W. (2005) Portrait of a Species: Chlamydomonas reinhardtii. Genetics, 170, 1601-1610.

https://doi.org/10.1534/genetics.105.044503

[6] Guide to Performing Relative Quantitation of Gene Expression Using Real-Time Quantitative PCR (Applied Biosystems).

http://www3.appliedbiosystems.com/cms/groups/mcb_support/documents/general documents/cms_042380.pdf

[7] Livak, K.J. and Schmittgen, T.D. (2001) Analysis of Relative Gene Expression Data Using Real-Time Quantitative PCR and the $2^{-\Delta \Delta \mathrm{C}_{\mathrm{T}}}$. Methods, 25, 402-408.

https://doi.org/10.1006/meth.2001.1262

[8] Pfaffl, M.W. (2001) A New Mathematical Model for Relative Quantification in RealTime RT-PCR. Nucleic Acids Research, 29, e45.

https://doi.org/10.1093/nar/29.9.e45 
Submit or recommend next manuscript to SCIRP and we will provide best service for you:

Accepting pre-submission inquiries through Email, Facebook, LinkedIn, Twitter, etc. A wide selection of journals (inclusive of 9 subjects, more than 200 journals)

Providing 24-hour high-quality service

User-friendly online submission system

Fair and swift peer-review system

Efficient typesetting and proofreading procedure

Display of the result of downloads and visits, as well as the number of cited articles Maximum dissemination of your research work

Submit your manuscript at: http://papersubmission.scirp.org/

Or contact ojbiphy@scirp.org 